\title{
REPERCUSSÃO DA OSCILAÇÃO SUL NA PRECIPITAÇÃO DO SUDESTE BRASILEIRO: ANÁLISE PARA OS ANOS DE 2015 E 2016
}

\author{
Antonio Carlos Oscar Júnior ${ }^{\text {(a) }}$, Lucí Hidalgo Nunes ${ }^{\text {(b) }}$ \\ (a) Instituto de Geografia/Universidade do Estado do Rio de Janeiro, antonio.junior@uerj.br \\ (b) Insituto de Geociências/Universidade Estadual de Campinas , luci@ige.unicamp.br
}

\section{Eixo 3: Climatologia em Diferentes Níveis Escalares: Mudanças e Variabilidades}

\begin{abstract}
Resumo
Anomalias de temperatura do oceano pacífico sul são um dos mais conhecidos padrões de telexonexão que afentam o clima em escala planetária. Em face desta importância e da necessidade de melhor compreensão dos impactos desse fenômeno, sobretudo no Sudeste brasileiro, este trabalho avalia a hipótese de ocorrência de anomalias pluviométricos nesta região em virtude da intensidade do fenômeno. Para isso, foi selecionado o evento ocorrido entre 2015 e 2016 (comparando-os ao período de 1948-2016), dando atenção aos trimestres com concentração da precipitação. Como estratégia metodológica, foram utilizados dados de reanálise do NCEP/NCAR aplicando teste de correlação entre o indíces de oscilação, precipitação e vetor de ventos em $850 \mathrm{mb}$ para as diverentes regiões do pacífico. Como resultados, destaca-se: anomalia positiva para janeiro de 2016 e o trimestre JFM (IOS +2.0), possivelmente associados à região Nino $1+2$; anomalia negativa no trimestre $\mathrm{SON}(\mathrm{IOS}+2.0)$, possivelemnte associado à região Niño 4.
\end{abstract}

Palavras chave: variabilidade; precipitação; circulação atmosférica; El Niño;

\section{Introdução}

A variabilidade é a principal característica do sistema climático terrestre, onde a permuta de energia e matéria, através das principais formas de transferência física, permite, por meio do comportamento fluído da atmosfera, que certos modos de variabilidade propaguem alterações temporárias nos padrões atmosféricos em diversos níveis espaciais (global, regional, local), bem como de duração (variações decadais e interdecadais, como a Oscilação Decadal do Pacífico, ou mais curtas, como a Oscilação Madden-Julian). De acordo com Philander (1998), o clima planetário depende da intereação de, pelo menos, cinco elementos: atmosfera, oceano, criosfera, continentes - adicionando a este último biosfera e hidrologia. Desse modo, mudanças em uma das componentes podem repercutir em retroalimentação positiva ou negativa, influenciando os padrões temporo-espacais dos climas ${ }^{1}$.

\footnotetext{
1 A variável astronômica também é importante para a variabilidade climática, visto que a radiação solar comanda todos os processos desencadeados neste sistema, de modo que os ciclos solares, igualmente promovem alterações dos padrões climáticos.
} 
Dada a representatividade de cobertura dos oceanos, ocupando mais de dois terços da superfície terrestre, Wells (1998) defende que "todas as escalas de movimentação atmosférica são envolvidas pela transferência de energia entre oceano e atmosfera, e por isso muitos fenômenos atmosféricos são respondidos, direta ou indiretamente, pela temperatura da superfície do mar (p.32). Dessa forma, é fundamental que na análise da variabilidade climática, sobretudo, em escala regional, essa componente seja incorporada, já que desencadeia anomalia na circulação atmosférica e, concomitantemente, nos padrões de distribuição dos elementos climáticos.

A interação atmosfera-oceano é um elemento importante para o entendimento das caracteríticas do clima na Região Sudeste do Brasil que, além disso, está localizada em uma área transicional do ponto de vista da escala zonal, já que é atravessada pelo Trópico de Capricórnio e na escala regional pelo confronto de sistemas tropicais e polares, trazendo consigo chuvas em geral, concentradas no tempo e espaço (SERRA e RATISBONNA, 1941; BRANDÃO, 1987; NIMER, 1979; SANT'ANNA NETO, 2005, NUNES et al., 2009). Outros sistemas, tais como as zonas de convergência de umidade também colaboram para a ocorrência desse padrão de pluviosidade, de modo, que devido a essa característica dinâmica do Sudeste brasileiro, é fundamental o desenvolvimento de estudos que busquem correlação e indícios da modulação dos eventos atmosféricos/climáticos desta região à temperatura da superfície do mar -TSM.

Dentre as anomalias relacionadas à TSM destaca-se o El Niño-Oscilação Sul, evento de grande escala e baixa frequência que, segundo Grimm (2009), é a fonte principal da variabilidade interanual da precipitação no Brasil. De acordo com a autora, em meses de janeiro sob atuação do El Niño há um fortalecimento da baixa térmica continental subtropical em função do aquecimento anômalo da superfície no período da primavera, induzindo a convergência de baixos níveis e movimentos ascendentes, desenvolvendo uma circulação ciclônica no Sudeste brasileiro, enquanto nos altos níveis prevalecem anomalias anticiclônica. Carvalho, Jones e Liebmann (2004), encontraram aumento da pluviosidade na região da ZCAS, influenciando no aumento do número de eventos extremos de precipitação (GRIMM et al., 2004). Malvestio (2013) avaliou a participação da ZCAS na promoção da precipitação na região sudeste brasileira, associando vários eventos calamitosos com a persistência desse fenômeno.

Embasados pela perspectiva supracitada, associado à necessidade apontada por Limberger (2016a) de novos avanços da climatologia no sentido da compreensão das teleconexões, esse estudo tem como objetivo avaliar se a oscilação ocorrida no Pacífico entre setembro de 2015 e março de 2016 promoveu algum impacto na pluviosidade do Sudeste brasileiro. Segundo dados divulgados pela agência NOAA (National Oceanic and Atmospheric Administration), o Índice de Oscilação Sul (IOS) variou entre -0,8 
(nos trimestres de agosto, setembro e outubro - ASO; setembro, outubro e novembro - SON e outubro, novembro e dezembro - OND) a +2,3 (no trimestre novembro, dezembro e janeiro - NDJ).

\section{Materiais e Métodos}

Utilizou-se dados disponibilizados pelo Climatic Data Center da NOAA que se referem ao projeto Reanálise I do NCEP/NCAR (KALNAY et al., 1996), especificamente os referentes à: taxa de precipitação $(\mathrm{mm} / \mathrm{dia})$, vetor de ventos em $850 \mathrm{mb}$ e temperatura da superfície do mar, os quais apresentam resolução espacial de $2^{\circ}$ e intervalo temporal de 1948 a 2016 e escala mensal.

Na primeira etapa, foram calculadas as anomalias de TSM em relação à série histórica de 19812010, para os anos de 2015 e 2016, e para os meses de dezembro de 2015 e janeiro de 2016, assim como para os trimestres de setembro, outubro e novembro - SON; outubro, novembro e dezembro - OND; novembro, dezembro e janeiro - NDJ; dezembro, janeiro e fevereiro - DJF e janeiro, fevereiro e março - JFM. O mesmo procedimento foi aplicado aos demais elementos: precipitação e vetor de ventos em $850 \mathrm{mb}$. A enfâse dada a esses trimestres tem respaldo nos estudos de Paiva (1997) e Alves (2002) indicando que a estação chuvosa no Sudeste brasileiro ocorre entre os meses de outubro e março, concentrando mais de $80 \%$ do volume de chuvas.

A segunda etapa consistiu no cálculo da correlação linear entre os dados de precipitação de 1948 a 2016 e o Indíce de Oscilação Sul - IOS, bem como os indíces das regiões Niños: 1+2, 3, 3.4 e 4, dando ênfase também aos meses de janeiro e dezembro e aos trimestres supracitados. O objetivo dessa etapa foi verificar se há correlação entre os dados e identificar se alguma região do pacífico equatorial explicaria melhor a correlação.

\section{Resultados}

Os resultados de anomalia da TSM (Fig. 1), em relação ao período de 1981-2010, para quase todos os períodos analisados confirma a ocorrência do fenômeno El Niño, caracterizado pelo aquecimento das águas do setor leste do pacífico equatorial, exceto para o ano de 2016. A explicação para esse resultado é plausível a partir dos dados do IOS, marcado pela ocorrência do fenômeno nos cinco primeiros meses do ano (mesmo assim com decréscimo dos valores), ocorrendo nos últimos meses do ano anomalia negativa, indicando a possibilidade de ocorrência 
da La Niña. Dando ênfase aos meses, dezembro de 2015 e janeiro de 2016 apresentaram as maiores anomalias de temperatura, o que se relaciona diretamente com os valores de o IOS de $+2,3$ e $+2,2$, respectivamente.

Quanto às anomalias da taxa de precipitação (Fig. 2), observa-se em dezembro de 2015 anomalia negativa no litoral do Sudeste, com, aproximadamente, $-2,0 \mathrm{~mm} /$ dia e um pequeno setor de Minas Gerais na ordem de $-4 \mathrm{~mm} /$ dia. Essa anomalia negativa aparece também nos trimestres SON e OND, com uma anomalia de $-2,0 \mathrm{~mm} /$ dia em uma área maior do Sudeste. Contudo, no mês de janeiro de 2016 e no trimestre de janeiro, fevereiro e março - JFM observa-se anomalia positiva da taxa de precipitação, na ordem de $+8,0 \mathrm{~mm} /$ dia e $+6,0 \mathrm{~mm} /$ dia. É valido destacar que para todos esses períodos o IOS esteve igual ou superior à +2.0 .
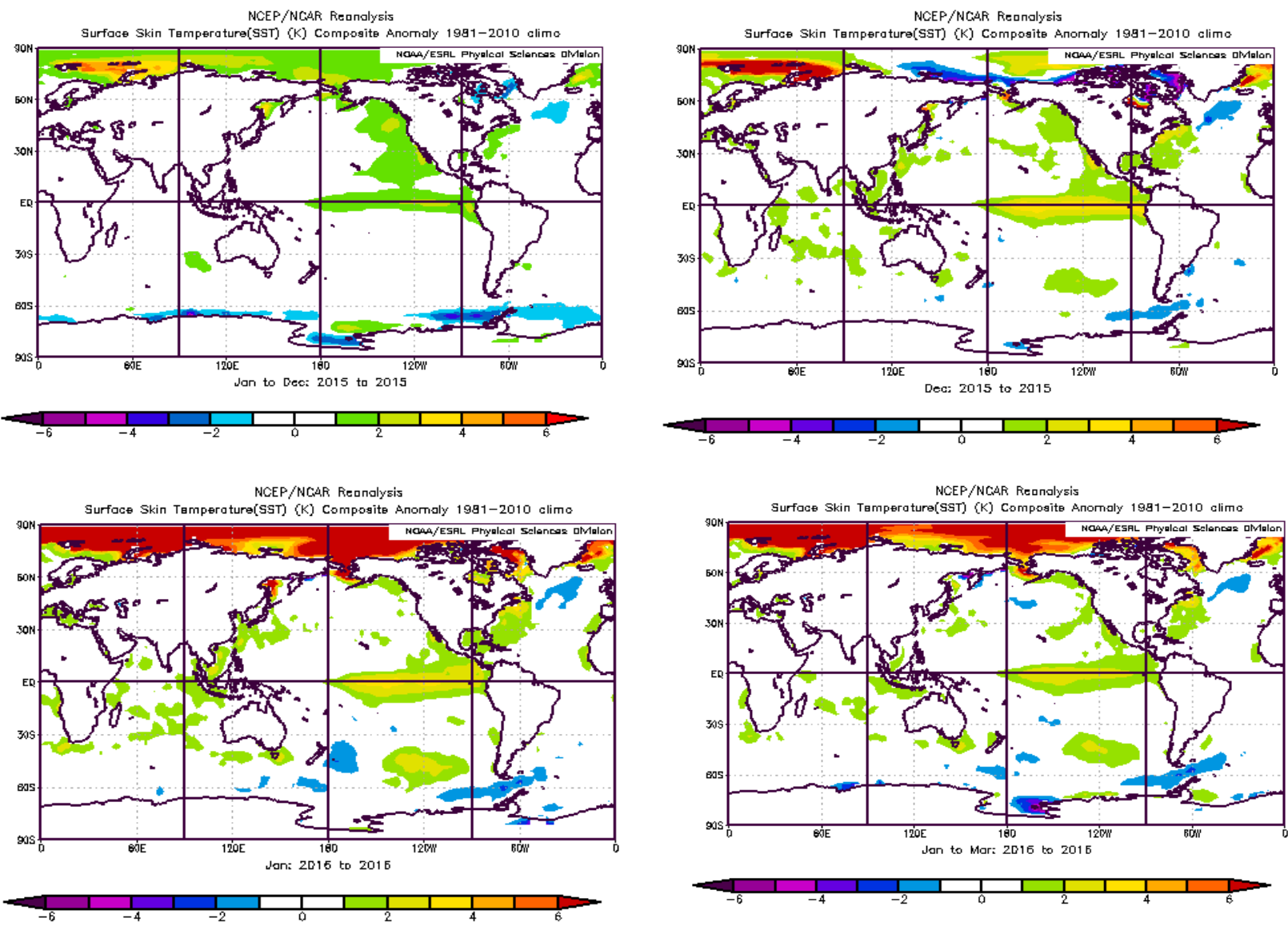

Figura 2 - Anomalia de TSM para: (a) o ano de 2015, (b) dezembro de 2015, (c) janeiro de 2016 e (d) JFM. 
No que diz respeito à circulação atmosférica de altos níveis (Fig. 3), através dos dados de vetor de ventos e velocidade é possível constatar a ocorrência de anomalia positiva na Alta da Bolívia (AB), com velocidade dos ventos superior a $4 \mathrm{~m} / \mathrm{s}$ no caso do trimestre de janeiro, fevereiro e março - JFM, e de $6,5 \mathrm{~m} / \mathrm{s}$ em janeiro de 2016. Já nos demais trimestres, sobretudo, SON, essa anomalia foi inferior a $2 \mathrm{~m} / \mathrm{s}$, indicando menor atividade deste sistema atmosférico. Tal constatação corrobora os resultados de Grimm (2006) a respeito da alteração do padrão de circulação atmosférica, de acordo com a intensidade do fenômeno - exatamente no período de maior valor de IOS, os resultados inferem sobre a maior atividade do fluxo anticiclonal (AB) em altos níveis e, consequentemente, o estabelecimento de uma área ciclonal em baixos níveis. Os vetores de vento indicam, também, para uma confluência dos ventos para o Sudeste, o que poderia estimular a formação de uma zona de convergência de umidade (tal como a ZCAS), canalisando umidade entre a Amazônia e o Atlântico Sul, conforme apontam Carvalho, Jones e Liebmann (2004).

Os resultados apresentados permitem avaliar a ocorrência de anomalia da taxa de precipitação, sobretudo anomalia positiva para o mês de janeiro de 2016 e para o trimestre JFM, acompanhados por anomalias de circulação atmosférica, a priori corroborando os resultados apontados pela literatura quando há ocorrência de El Niño. Já para o trimestre SON, com anomalia negativa, observou-se uma menor atividade da $\mathrm{AB}$, indicando um mecanismo atmosférico inverso ao período de anomalia positiva. Dessa forma, não se descarta a hipótese de que, dependendo da magnitude do evento e Niño de influência, é plausível a ocorrência de padrões de anomalia positiva na pluviosidade da área de estudo.

No entanto, com objetivo de melhor respaldar os resultados obtidos, optou-se pela aplicação do teste de correlação linear para a taxa de precipitação do período de 1948 a 2016 e os índices: IOS e das regiões denominadas Niños. Para o IOS (Fig. 4), os resultados apontam para uma correlação negativa $(-0,2)$, pouco expressiva, para os valores anuais e meses de janeiro, caracterizando uma relação inversamente proporcional entre taxa de precipitação e IOS para esses períodos. Já para os trimestres SON e OND, o teste indicou correlação positiva $(+0,5)$, expressiva, ou seja, para esse período, taxa de precipitação e IOS apresentam proporcionalidade direta. Os demais períodos não apresentaram correlação. 

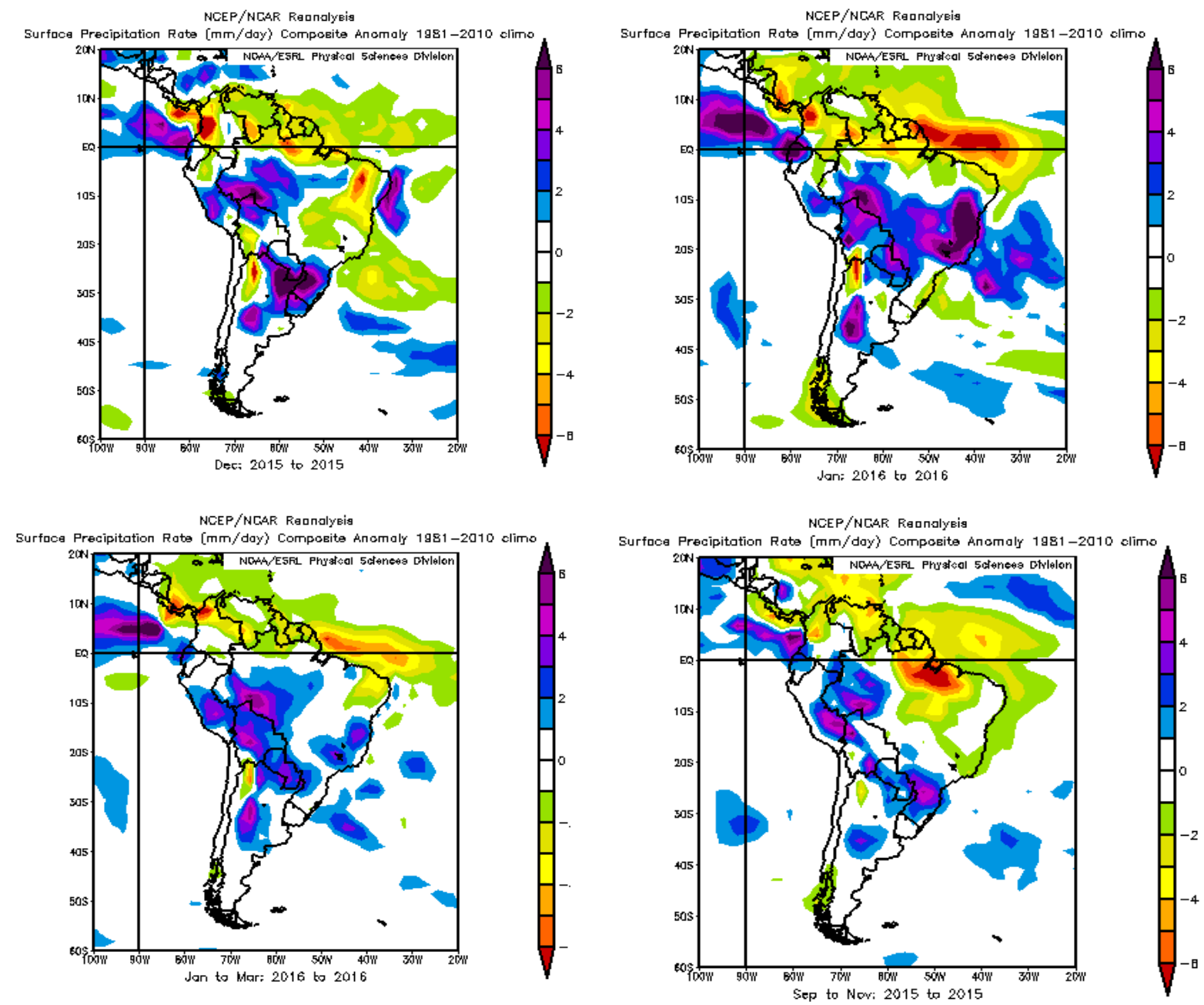

Figura 3 - Anomalia na taxa de precipitação (mm/dia) para: (a) dezembro de 2015, (b) janeiro de 2016, (c) JFM 2016 e (d) SON 2015.

NCEP/NCAR Rannalyeis

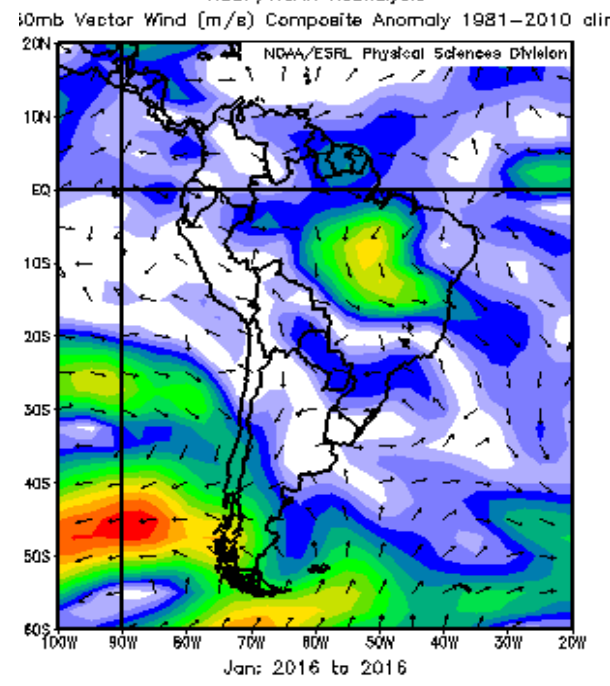

NCEP/NCARR Rennalyeis

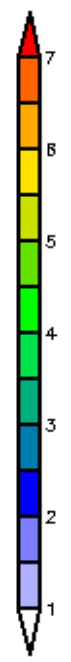

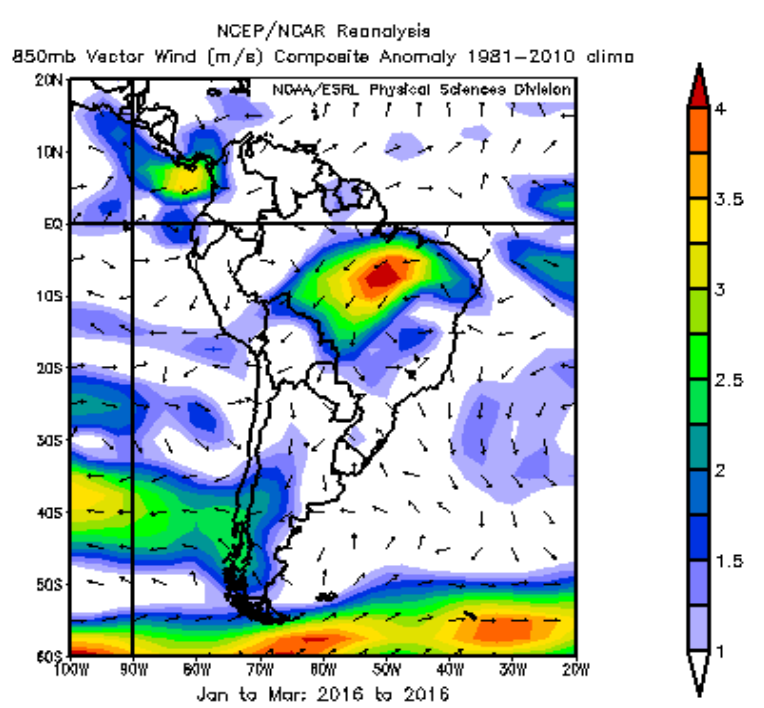

Figura 4 - Anomalia no vetor de ventos (m/s) em: (a) janeiro de 2016 e (b) JFM. 

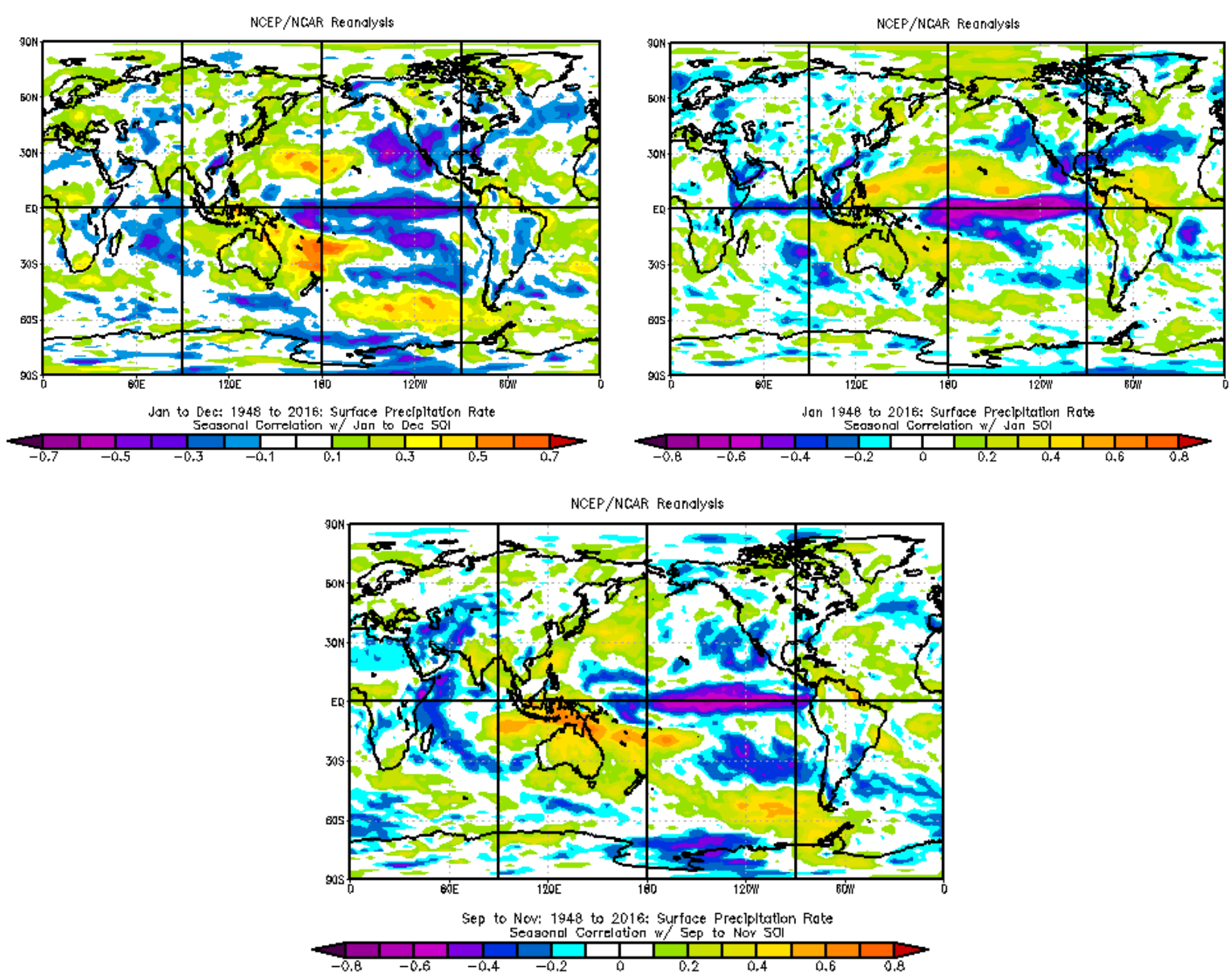

Figura 5 - Correção linear entre taxa de precipitação (mm/dia) para intervalo: (a) anual, (b) meses de janeiro e (c) trimestres de SON do período de 1948 a 2016.

Outrossim, seguindo Limberger et al. (2016b), o IOS calculado por outros centros de pesquisa nem sempre apresentam resultados consistentes às diversas propostas de pesquisa. Assim, optouse pelo detalhamento da correlação para as diferentes regiões de estudo do fenômeno, denomiados de niños: 1+2, 3, 3.4 e 4, na tentativa de, a partir da série histórica, fundamentar os resultados encontrados para a transição de 2015 para 2016.

Entre os resultados obtidos, podemos destacar que: 1) o Niño 1+2 tem correlação positiva com a taxa de precipitação dos meses de janeiro (entre $+0,2$ e $+0,5$ ) entre 1948 e 2010, bem como dos trimestres DJF (entre $+0,2$ e $+0,5$ ), JFM (entre $+0,2$ e $+0,5)$ e NDJ $(+0,2)$ do período entre 1948 e 2010 (Fig. 6); 2) o Niño 3 apresenta correlação positiva para os mêses de janeiro $(+0,2)$ e os 


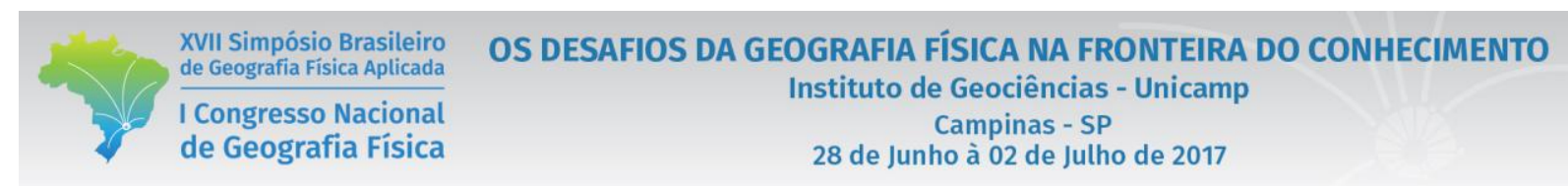

trimestres de DJF $(+0,2)$ (Fig. 7); 3 - o Niño 3.4 apresenta correlação positiva com os meses de janeiro $(+0,2)$ (Fig. 8) e, finalmente, o Niño 4 apresenta correlação positiva com os meses de janeiro (entre $+0,2$ e $+0,4$ ) e dezembro (entre $+0,2$ e $+0,4$ ), bem como o trimestre de dezembro, janeiro e fevereiro - DJF (entre $+0,2$ e $+0,4$ ). Este último Niño apresenta ainda uma correlação negativa para os trimestres setembro, outubro e novembro - SON (entre -0,1 e -0,3) entre 1948 e 2010 (Fig. 9).
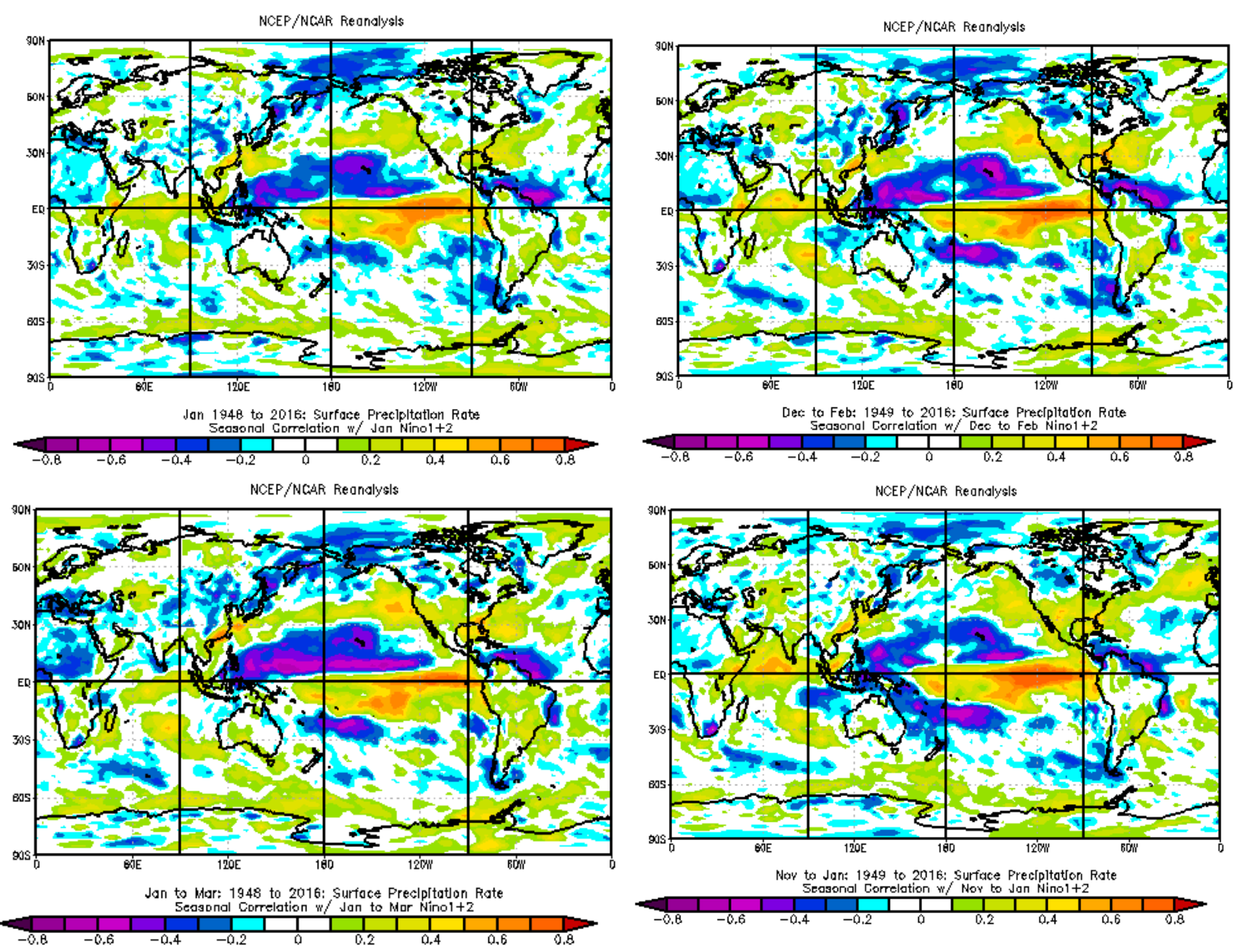

Figura 6 - Correlação da taxa de precipitação (mm/dia) e a oscilação Niño 1+2: (a) janeiro, (b) JFM, (c) DJF, (d) NDJ. 

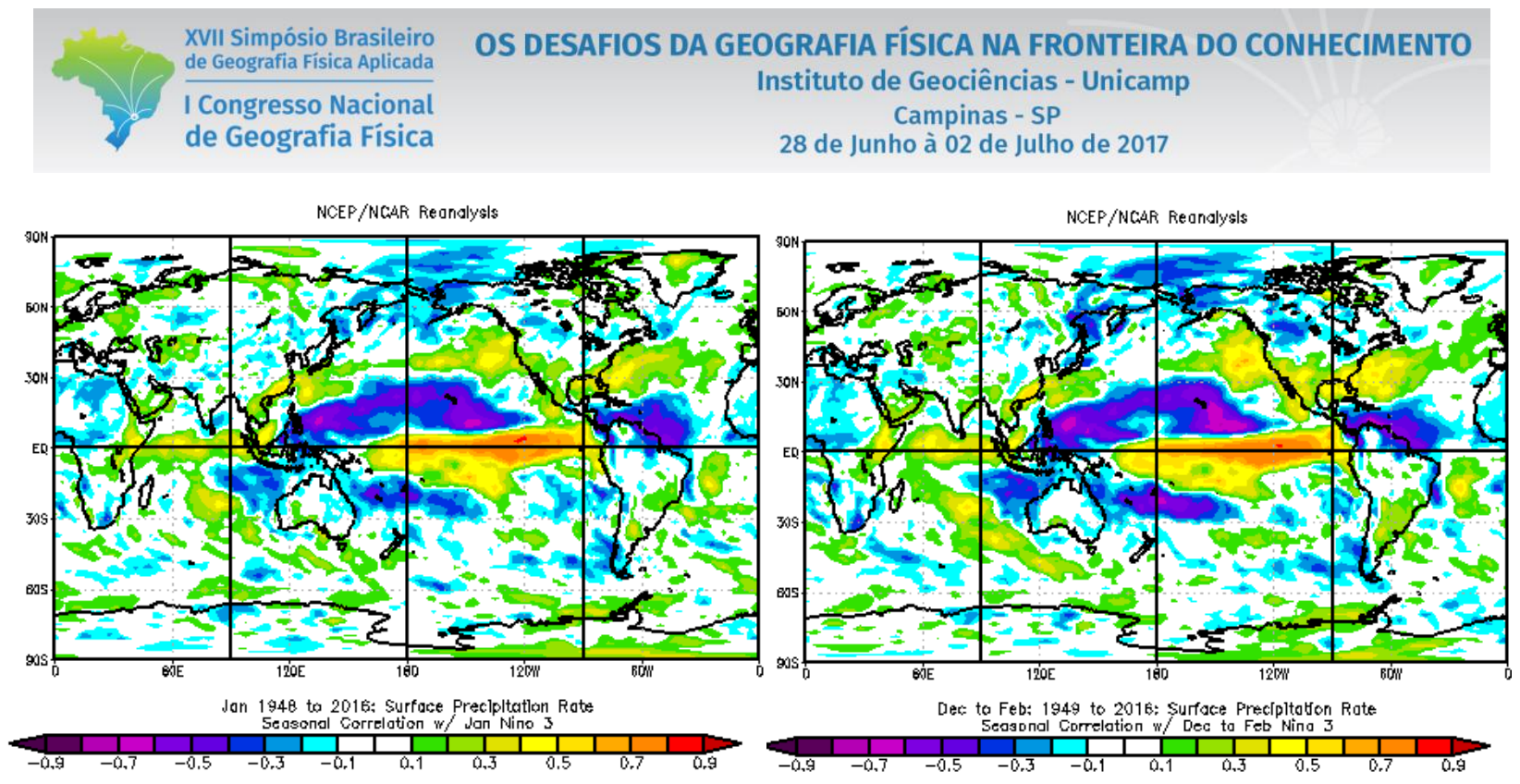

Figura 7 - Correlação da taxa de precipitação (mm/dia) e as oscilações do Niño 3 para: (a) janeiro e (b) DJF.

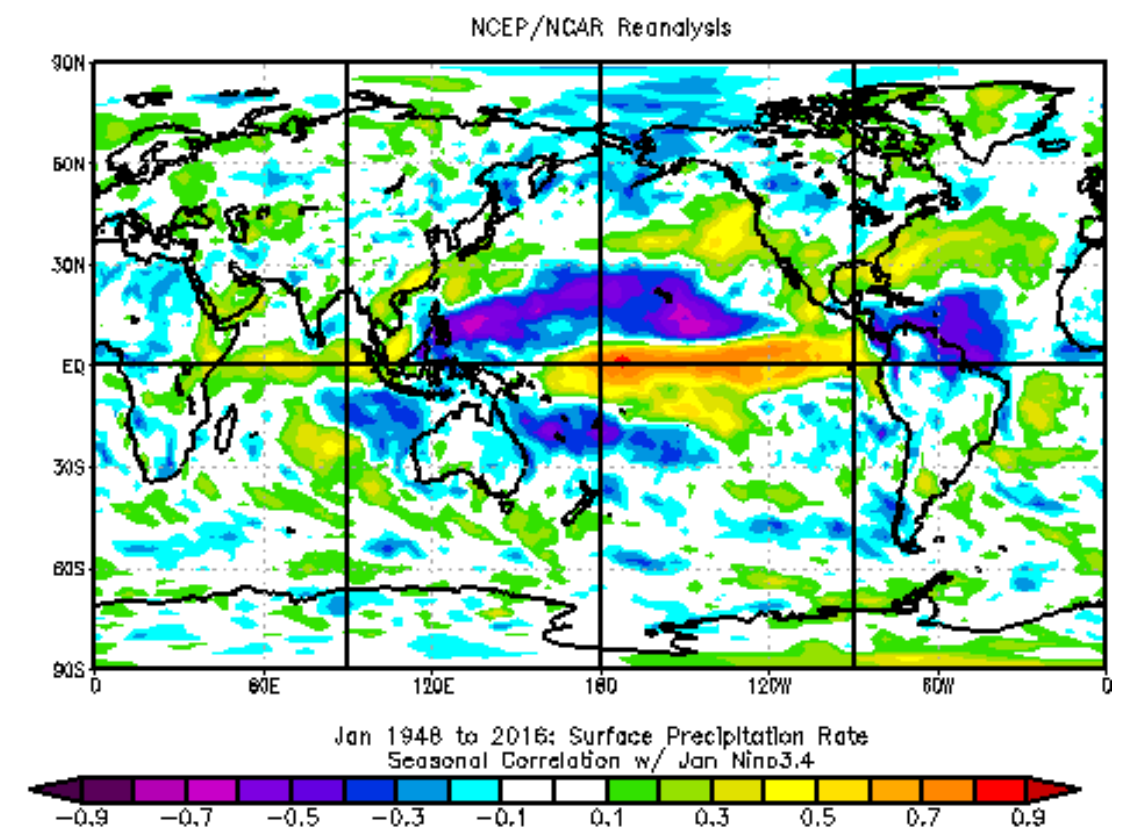

Figura 8 - Correlação da taxa de precipitação (mm/dia) e as oscilações do Niño 3.4 para: (a) janeiro. 

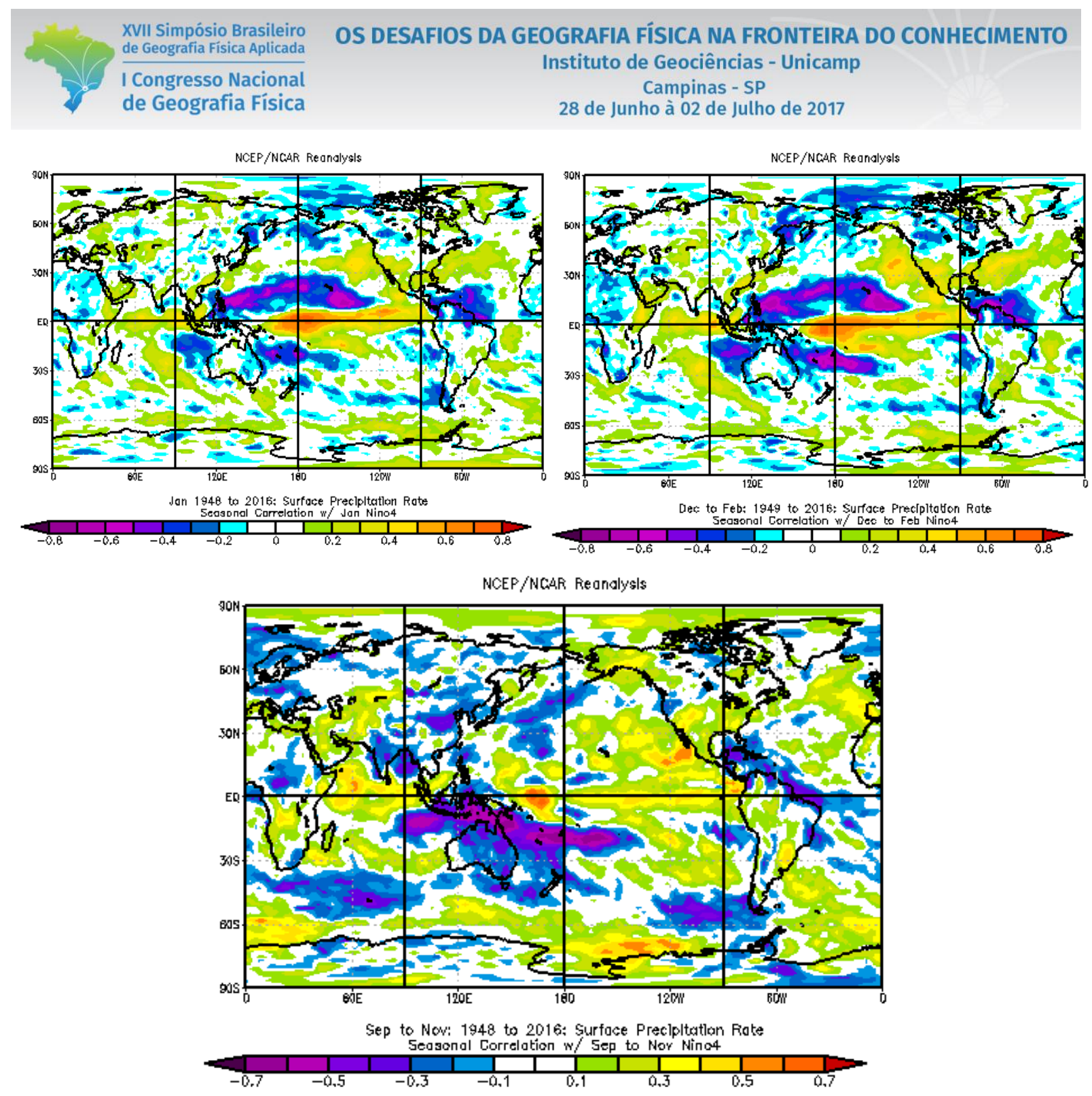

Figura 9 - Correlação da taxa de precipitação (mm/dia) e as oscilações do Niño 4 para: (a) janeiro, (b) DJF e (c) SON.

\section{Considerações Finais}

O estudo teve por objetivo avaliar o impacto do El Niño - Oscilação Sul na precipitação do Sudeste brasileiro para a transição do ano de 2015 para 2016. A partir dos dados de reanálise do NCEP/NCAR foi possível observar a ocorrência de anomalia na taxa de precipitação do mês de janeiro de 2016 e para o trimestre de JFM, bem como, anomalias negativas para dezembro e o trimentre de SON. A partir dos testes de correlação, no entanto, não foi possível concluir que todas as anomalias são explicadas a partir do fenômeno El Niño. 
O resultado das correlações apontou para uma correlação positiva entre o IOS e o trimestre chuvoso SON (a partir das taxas de precipitação), assim como o Niño 4 apresentou uma correlação negativa indicando, a priori, que quando ocorre o aumento de IOS há incremento na taxa de precipitação. No entanto, quando na região do Niño 4 prevalece a oscilação esse padrão é alterado, reduzindo a taxa de precipitação na área de estudo. Já o trimestre JFM apresenta correlação consideravel com o Niño $1+2$, indicando, em princípio, que quando prevalece a oscilação nessa região há anomalia positiva na taxa de precipitação.

A partir desses resultados é possível constatar que a Oscilação Sul não explica todos os eventos de anomalia positiva e negativa na taxa de precipitação do Sudeste brasileiro, o que indica complexidade maior da precipitação da área de estudo. Desse modo, é fundamental prosseguir com a análise de outros padrões de teleconexões, com vistas à compreensão da dinâmica pluviométrica desta região, favorecendo a previsão do tempo, bem como, o planejamento rural e urbano.

\section{Bibliografia}

ALVES, L. M.; MARENGO, J. A.; CASTRO, C. A. C. Início das chuvas na região Sudeste do Brasil: análise climatológica. In: CONGRESSO BRASILEIRO DE METEOROLOGIA, 12, Foz do Iguaçu. Anais... Foz do Iguaçu: SBMET, 2002.

BRANDÃO, A. M. P. M. Tendências e oscilações climáticas na área metropolitana do Rio de Janeiro. 1987. 385f. Dissertação (Mestrado em Geografia Física) - Faculdade de Filosofia, Letras e Ciências Humanas, Universidade de São Paulo, São Paulo, 1987.

CARVAlHO, L. M. V.; JONES, C.; LIEBMANN, B. The South Atlantic Convergence Zone: intensity, form, persistence and relationship with Intraseasonal to interanual activity and extreme rainfall. Journal of Climate, v. 17, p.: 88-108, 2004.

GRIMM, A. M. Variabilidade interanual do clima no Brasil. In: CAVALCANTI, I. F. A.; FERREIRA, N. J.; SILVA, M. G. A. J \& DIAS, M. A. F. S (orgs.). Tempo e Clima no Brasil. São Paulo: Oficina de Textos, 2009, p.353-382.

GRIMM, A.M.; TEDESCHI, R.G. Influência de eventos El Nino e La Nina sobre a frequência de eventos extremos de precipitação no Brasil. In: CONGRESSO BRASILEIRO DE METEOROLOGIA, 13, 2004, Fortaleza. Anais... Fortaleza: SBMET, 2004. 
KALNAY, E. The NCEP/NCAR 40-year Reanalysis Project. Bulletin of the American Meteorological Society.Vol. 77, n. 3, p.437-471, mar. 1996.

LIMBERGER, L. Estudo de teleconexões atmosférica e possibilidade de avanços na climatologia geográfica: conceitos, fonte de dados e técnicas. Revista Brasileira de Climatologia, Paraná, v. 19, julho/dezembro. 2016a.

LIMBERGER, L. Variabilidade climática na bacia amazônica brasileira: teleconexões com a temperatura da superfície dos mares. In: XII CONGRESSO BRASILEIRO DE CLIMATOLOGIA GEOGRÁFICA, 12, 2016, Goiânia. Anais...Goiânia: ABClima, 2016.

MALVESTIO, L. M. Variabilidade da precipitação pluviométrica da região sudeste do Brasil no período chuvoso e suas consequências ambientais. Dissertação (Mestrado em Geografia) - Instituto de Geociências, Universidade Estadual de Campinas, Campinas, 2013.

NIMER, E. Climatologia do Brasil. Rio de Janeiro: IBGE, 1979.

NUNES, L.H., KOGA-VICENTE, A., CANDIDO, D. H. Clima da Região Sudeste do Brasil. In: CAVALCANTI, I. F. A.; FERREIRA, N. J.; SILVA, M. G. A. J \& DIAS, M. A. F. S (orgs.). Tempo e Clima no Brasil. São Paulo: Oficina de Textos, 2009, p. 243-258.

PAIVA, C. M. Determinação das datas de início e fim da estação chuvosa e da ocorrência de veranicos na Bacia do Rio Doce. 1997. 65f. Dissertação (Mestrado em Meteorologia Agrícola) - Faculdade de Engenharia Agrícola, Universidade Federal de Viçosa, Viçosa, 1997.

PHILANDER, S.G. Is the temperature rising? The uncertain science of global warming. New Jersey: Princeton University Press. 1998.

SANT'ANNA NETO, J. L. Decálogo da climatologia do sudeste brasileiro. Revista Brasileira de Climatologia, Paraná, v.1, p.: 43-60, julho/dezembro. 2015.

SERRA, A.; RATISBONNA, L. O clima do Rio de Janeiro. Serviço de Meteorologia, Ministério da Agricultura, 1941.

WELLS, N. The atmosphere and ocean: a physical introduction. $2^{\mathrm{a} e d . ~ C h i c h e s t e r: ~ J o h n ~ W i l e y ~ \& ~ S o n s, ~} 1998$. 